ENCYCLOPEDDIE Encyclopédie berbère

BERBERE

$23 \mid 2000$

23 | Hiempsal - Icosium

\title{
Hin Tata
}

\section{M.-J. Viguera-Molins}

\section{OpenEdition}

Journals

Édition électronique

URL : http://journals.openedition.org/encyclopedieberbere/1595

DOI : 10.4000/encyclopedieberbere.1595

ISSN : 2262-7197

\section{Éditeur}

Peeters Publishers

\section{Édition imprimée}

Date de publication : 1 octobre 2000

Pagination : 3469-3470

ISBN : 2-7449-0207-1

ISSN : 1015-7344

\section{Référence électronique}

M.-J. Viguera-Molins, "Hin Tata », Encyclopédie berbère [En ligne], 23 | 2000, document H52, mis en ligne le 01 juin 2011, consulté le 24 septembre 2020. URL : http://journals.openedition.org/ encyclopedieberbere/1595; DOI : https://doi.org/10.4000/encyclopedieberbere.1595

Ce document a été généré automatiquement le 24 septembre 2020

(c) Tous droits réservés 


\section{Hin Tata}

\section{M.-J. Viguera-Molins}

1 Confédération berbère, appartenant au groupe Mașmūda, ainsi que le mentionne le Kitāb al-ansāb d'al-Magīì (470/1077-1078) (cf. Ibn 'Abd al-Ḥalīm, Kitāb al-ansāb, 221). L'ancêtre de cette confédération, dont le nom est transcrit en caractères arabes "Hintāt", était appelé "Yintī" dans la "langue des Mașāmida". Neuf clans (butūn) composaient la confédération des Hintāta, parmi lesquels ceux de Gaygāya et de Wuzkīta. Le lieu d'origine des Hintāta doit précisément correspondre au territoire de ces deux clans, établis au sud de Marrākuš. Au temps des Banū Marīn, les émirs Hintāta dominaient le territoire de Marrākuš depuis le Jabal Hintāta, dans le Haut Atlas.

2 Les Hintāta accédèrent à la scène historique au début du xiI ${ }^{\mathrm{e}}$ siècle, quand leurs principaux šaykh-s, Wānūdīn b. Yansilt, Namīr b. Dāwūd, Abū Māgalīfa et Faska U-Mzal, appuyèrent le Mahdī almohade, Muḥammad b. Tūmart, à partir de 517/1123. Ce dernier, le šaykh Faska, adopta dorénavant le nom d'un célèbre compagnon du Prophète Muḥammad et, sous sa nouvelle dénomination de Abū Ḥafș 'Umar b. Yahyyà, contribua au triomphe des Almohades, occupant dans leur État des postes de responsabilité et de prestige - ayant été principalement le bras droit du calife 'Abd alMu'min - jusqu'à sa mort en 571/1181. Ce šaykh hintātī, Abū Ḥafș 'Umar, fut l'ancêtre des Ḥafșides, gouverneurs de Tunis depuis 627/1224, où ils s'installèrent comme dynastie indépendante de 627/1229 à 981/1573.

3 Formant un détachement spécial des armées almohades, les Hintāta participèrent à leur expansion en Afrique du Nord et à leur triomphe. Ils passèrent aussi en al-Andalus, où ils sont expressément mentionnés à propos de quelques campagnes, comme celle de 579/1184, conduites avec des troupes amenées du Maghreb par le calife Abū Ya'qūb, qui s'acheva par sa défaite et sa mort devant Santarem. Pourtant, la présence des Hintāta n'a pas laissé de traces dans la toponymie de la Péninsule ibérique. Les Hintāta furent impliqués dans les luttes dynastiques entre prétendants almohades dès la première moitié du VII/XIII ${ }^{e}$ siècle. Un petit-fils du šaykh hintātī Abū Ḥafș 'Umar, appelé Ibn al Šahīd, appuya depuis le Maghreb le calife almohade al-'̄Adil, insurgé à Murcie (621/1224), jusqu'à ce qu'il occupe Marrākuš, où il fut assassiné (624/1227). Ensuite Ibn al-šahīd proposa Yaḥyà b. al-Nāșir comme calife, retirant son agrément antérieur à al- 
Ma'mūn, lequel, lorsqu'il entra dans Marrākuš (1229), ordonna l'exécution d'une centaine de šaykh-s, en particulier des Hintāta et des Tinmel, ainsi que leurs familles.

Après les Almohades, les Hintāta conservèrent leur puissance puisqu'une de leurs familles, les Awlād Yūnus, famille qui semble descendre du šaykh hintātī Abū Ḥaf̦̣ 'Umar, rendit des services politiques et fiscaux aux Mérinides.

Le sultan Abū 1- Ḥasan al-Marīnī se réfugia chez eux après avoir été battu par son fils, le sultan Abū 'Inān en 751/1350 ; et, dans le Jabal Hintāta, Abū l-Hasan, jusqu'à sa mort en ce même endroit en 1351, fut protégé par 'Āmir b. Muḥammad ibn 'Alī, šaykh puissant des Hintāta. Quand le sultan Abū 'Inān mourut (759/1358), le royaume fut divisé entre plusieurs fils et le sud du Maghreb échut à Muhammad al-Mu'tamid qui s'installa à Marrākuš, soutenu et conseillé par ce šaykh des Hintāta ('Ibar, VII, 622-627), 'Āmir, déjà cité qui, en 761/1360, reçut la visite, dans la "montagne des Hintāta", du vizir et écrivain grenadin Ibn al-Khatīb, lequel nous a laissé un portrait élogieux de lui et de ses gens, "soutiens de la da'wa [almohade], amis intimes de la dynastie des Mérinides".

6 'Āmir al-Hintātī participa ensuite aux intrigues dynastiques Mérinides, ce qui lui valut d'être officiellement reconnu, jusqu'en 763/1362, par le tout-puissant vizir al-Yābānī "gouverneur de toute la partie du Maghreb située au-delà de l'Umm Rabīa", en même temps qu'il lui confiait la garde du prince mérinide Abū 1-Faḍl, qui avait été chargé de gouverner Marrākušs. Ainsi se mit en place, sous l'égide des Mérinides, une époque de prépondérance des Hintāta sur le sud du Maghreb, sous la direction de la branche hintāta des Awlād Yūnus qui, parallèlement à d'autres dynasties locales, "gouvernaient en montagne pour le compte du sultan en attendant de se rendre indépendantes" (Kably, Société, 234). En effet, le šaykh 'Āmir finit par se soulever contre les Mérinides qui s'emparèrent de lui pour finalement le mettre à mort en 771/1370, bien que sa famille réussît à se maintenir à la tête de la tribu, de plus en plus détachée du pouvoir central, lequel déclinait progressivement.

7 Les Hintāta, "rois de Marrākuš", virent leur pouvoir se réduire à cette seule ville et à son territoire environnant, tandis qu'ils devaient s'affronter, sans beaucoup de succès, aux Portugais, qui attaquèrent Marrākuš en 921/1515. Le soutien des Sa'diens permit aux Hintāta de maintenir leur pouvoir sur la cité pendant dix ans encore, jusqu'à ce que les Sa'diens eux-mêmes occupassent Marrākuš, donnant la mort à Muḥammad b. al-Nāṣ ir Bū Šantūf, dernier amīr des Hintāta, dont la famille fut envoyée à Taroudant. Les Hintāta, depuis, disparaissent des sources écrites maghrébines et les traces de cette confédération s'évanouissent: à l'époque contemporaine, on n'utilise plus le nom "Hintāta" au Maroc où, pourtant, sont bel et bien mentionnés quelques-uns de leurs clans (butūn), notamment celui de Gaygāya, qui ont acquis à leur tour la qualité de tribu (qabila). Quelques familles (usra) conservent encore le souvenir traditionnel de leur appartenance aux Hintāta, en particulier dans la ville de Sfax (Șfāqs), en Tunisie. 


\section{BIBLIOGRAPHIE}

IBN AL-QATTAN, NaẒm al-ŷumān, ed. Makkī Benuti, 1990, p. 82, 84, 86, 133-137, 239.

IBN SAHIB AL-SALAT, Ta'rīj al-mann bi-I-imāma, ed ' A-H. al-Tāzī, Beyrouth, 1987, 44, 69, 117, 199, 206, $331,405,406,439$.

AL-MARRAKUSI, al-Mu' $\hat{y} i b$, ed. M. S. al- ${ }^{\mathrm{C}}$ Aryān y M. al- ${ }^{\mathrm{C}}$ Alamī, Le Caire, 1963, 340-341.

IBN ABI ZAR' ${ }^{\mathrm{c}}$, al-Anīs al-mutrib, Rabat, 1972, 178, 226-227.

IBN CIDARI, al-Bayān al-mugrib, Beyrouth-Casablanca, 1406/1985, p. 9, 158, 285, 317, 327, $352,369$.

IBN KHALDUN, ${ }^{C} I b a r$, VII, p. 648-655, 661-663.

IBN AL-KHATIB, Iḥāța, El Cairo, ed.

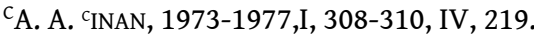

IBN AL-KHATIB, Nufāọatat al-ŷirab, 269-280.

IBN ${ }^{\mathrm{C}} \mathrm{ABD}$ AL-HALIM, (s. VIII/XIV), Kitāb al-ansāb, edición y estudio M. Ya'là, Tres textos árabes sobre beréberes en el Occidente islámico, Madrid, 1996, 221 p.

CÉNIVAL P. (de), “Les émirs des Hintāta, ‘rois'de Marrakech”, Hespéris, XXIV-4 (1937), p. 245-257.

HUICI MIRANDA A., Historia política del Imperio almohade, Tetuán, 1957, I, p. 60, 68-70, 73, 77-78, 85, 103, $142,168,181 ; \mathrm{II}, 473$.

DEVERDUN G, “Hintāta”, Encyclopédie de l'Islam, 2nd. ed., III, 478.

CABD AL-WABHAB B. MANSUR, Qabā’il al-Magrib, Rabat, 1388/1968, I, 168, 326-327, 328.

KABLY M., Société, pouvoir et religion au Maroc à la fin du Moyen Âge (XI ${ }^{e}-X V^{e}$ siècle), Paris,1986, 16, 18, $21,20,24,25,29,38,44,133,151,173,193,234,244,254$.

VIGUERA M.-J., "Ibn al-Kֵhâț̣ib visita el Monte de los Hintāta”, Homenage J.-M. Fórneas Besteiro, Granada, 1995, 645-659.

FELIPE H. (de), Identidad y onomástica de los beréberes de al-Andalus, Madrid, 1997.

VÉRONNE Ch. (de la), Histoire sommaire des Sac diens au Maroc. La première dynastie chérifienne-1511-1659, Paris, 1997, 20.

INDEX

Mots-clés : Histoire médiévale, Maroc, Roi 